\title{
Comparison with Crystallization of Calcium and Strontium Carbonates under DPPC Langmuir Monolayers
}

\author{
Zhonghui Xue ${ }^{1,2}$ \\ ${ }^{1}$ Shanghai Research Institute of Publishing Media, Shanghai, China \\ ${ }^{2}$ Shanghai Publishing and Printing College, Shanghai, China \\ Email: hnlgxzh@163.com
}

How to cite this paper: Xue, Z.H. (2020) Comparison with Crystallization of Calcium and Strontium Carbonates under DPPC Langmuir Monolayers. Open Access Library Journal, 7: e6216.

https://doi.org/10.4236/oalib.1106216

Received: June 29, 2020

Accepted: July 3, 2020

Published: July 6, 2020

Copyright $\odot 2020$ by author(s) and Open Access Library Inc.

This work is licensed under the Creative Commons Attribution International License (CC BY 4.0).

http://creativecommons.org/licenses/by/4.0/ (c) (i) Open Access

\begin{abstract}
In this paper, using Langmuir monolayers of dipalmitoylphosphatidylcholine (DPPC) as template, we have investigated the controlled crystallization of calcium and strontium carbonates to understand the biomineralization process at the inorganic-organic interface better. Although the calcite with a well-oriented (104) crystal plane has been obtained, as for the strontium carbonates, DPPC monolayers have resulted in the formation of the flower-like assemblies of strontianite needles; however, the oriented growth under the monolayers has not appeared. Using the lattice matching and electrostatic interaction at the inorganic-organic interface, we have discussed the possible mechanism of the phenomena.
\end{abstract}

\section{Subject Areas}

Analytical Chemistry

\section{Keywords}

Crystallization, Calcium Carbonates, Strontium Carbonates, DPPC, Langmuir Monolayers

\section{Introduction}

There is sustained interest in understanding natural biomineralisation processes [1] [2] [3]; many studies have been carried out on the synthesis and characterization of the biominerals in detail [4] [5] [6] [7] [8]. However, due to the complex interaction between the organic substances and the inorganic components, the mechanism of formation of minerals in biological systems is still unclear; a num- 
ber of questions await satisfactory answers. To mimic the biomineralization processes in model experiments, many different templates have been used, some examples of which are Langmuir [9] and Langmuir-Blodgett (LB) monolayers [10], self-assembled monolayers (SAMs) with differing terminal functionality [11], polymer surfaces [12] and so on. Langmuir monolayer and Langmuir-Blodgett monolayer, which can provide a more ideally flat organic surface with controllable chemical composition and molecular density [13], is an excellent template to investigate the relationships between the structure of the substrate and the overgrowing crystals. Therefore, LB technique has become an important means in biomimetic synthesis of innovative materials and detailed understanding of the mechanism in biomineralization.

Calcium carbonate is one of the most abundant biominerals; much attention has been focused on growth of $\mathrm{CaCO}_{3}$ crystals using biomimetic strategy [14] [15] [16]. As we all know, $\mathrm{CaCO}_{3}$ exists in a variety of polymorphic forms, calcite, vaterite and aragonite, an amorphous form of calcium carbonate also exists. Even though $\mathrm{SrCO}_{3}$ itself is not an important biomineral, $\mathrm{SrCO}_{3}$ crystallises from solution uniquely in the strontianite modification, which is isostructural with aragonite [17] [18]. Therefore $\mathrm{SrCO}_{3}$ is a simpler prototypical system than the more thoroughly studied $\mathrm{CaCO}_{3}$, and it might be interesting to compare the crystallisation of $\mathrm{SrCO}_{3}$ in the aragonite strontianite modification with the crystallisation of $\mathrm{CaCO}_{3}$ in all three modifications. The morphology and structure of the crystallization product provide insights into the processes proceeding at the inorganic-organic interface.

In this manuscript, we compared the controlled crystallization of calcium and strontium carbonates under DPPC Langmuir monolayer which is similar to lipid domains of cellular membranes [19]. More interestingly, we observed that the calcium carbonate can form well oriented single-crystalline calcite with the rhombohedral shape. Nevertheless, the flower-like strontianite has been obtained.

\section{Experimental Section}

\subsection{Materials}

DPPC was purchased from Sigma Chemical Co. and used without further purification, $\mathrm{CaCO}_{3}$ and $\mathrm{SrCO}_{3}$ were purchased from Tianjin Chemical Plant. Triply-deionized water (resistivity of $18.2 \mathrm{M} \Omega \cdot \mathrm{cm}^{-1}$ ) was obtained from MilliQ ultra-pure water system (Millipore, USA).

\subsection{Preparation of Supersaturated Solutions}

Supersaturated solutions of calcium bicarbonate and Strontium bicarbonate were prepared according to the procedures of Kitana [20] and they can briefly describe as follows: carbon dioxide gas was bubbled through a stirred aqueous suspension of $\mathrm{CaCO}_{3}$ or $\mathrm{SrCO}_{3}$ for 24 hours. The suspensions were then filtered and filtrate purged with $\mathrm{CO}_{2}$ gas for 0.5 hours to dissolve any remaining crystals. 
The $\mathrm{Ca}^{2+}$ or $\mathrm{Sr}^{2+}$ concentration of the resulting supersaturated solution is 4.0 $\mathrm{mM}$.

\subsection{Experimental Procedures}

The Supersaturated solutions were transferred to the LB trough (KSV mini-trough) at room temperature. Then using a microsyringe, the monolayer of DPPC was carefully and slowly spread from the $1.0 \times 10^{-3} \mathrm{M}$ solution in chloroform and its state was monitored by the LB system through its $\pi$-A curve. After the chloroform was evaporated for $15 \mathrm{~min}$, the monolayer was slowly and carefully compressed to the targeted pressure $(30 \mathrm{mN} / \mathrm{m})$. With the pressure held for $24 \mathrm{~h}$, crystals grown under the Langmuir monolayer were transferred in the $\mathrm{Y}$ type to clean glass slides. The as-prepared samples were characterized by X'Pero Philips X-ray diffractometer (Philips Ltd. Holand) and JSM-5600LV scanning electron microscopy (Jeol. Ltd. Japan).

\section{Results}

\subsection{The $\pi$-A Isotherms of DPPC on Different Subphase}

$\pi$-A isotherms of DPPC monolayers were obtained on pure water and the $\mathrm{Ca}\left(\mathrm{HCO}_{3}\right)_{2}, \mathrm{Sr}\left(\mathrm{HCO}_{3}\right)_{2}$ supersaturated aqueous solution, and they are shown in Figure 1.

The mean areas of DPPC per molecule obtained by extrapolating the slopes of the isotherms to zero pressure are found to be $34 \mathrm{~A}^{2}$ on pure water and $68,59 \mathrm{~A}^{2}$ on $\mathrm{Ca}\left(\mathrm{HCO}_{3}\right)_{2}$ and $\mathrm{Sr}\left(\mathrm{HCO}_{3}\right)_{2}$ supersaturated aqueous solution, respectively. Evidently, the mean molecular areas of DPPC on these supersaturated aqueous solutions are larger than that on pure water, which indicated that there is very

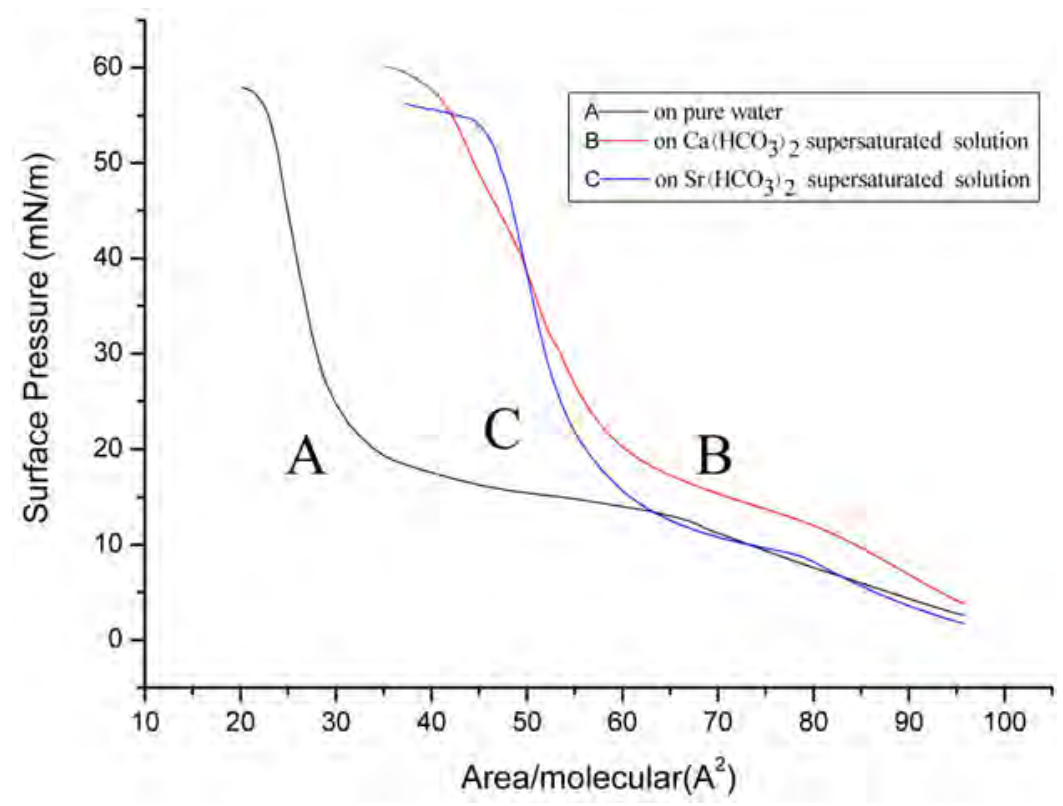

Figure 1. $\pi$-A isotherms of DPPC monolayers on different subphase. (A) Pure water, (B) $\mathrm{Ca}\left(\mathrm{HCO}_{3}\right)_{2}$ supersaturated solution, (C) $\mathrm{Sr}\left(\mathrm{HCO}_{3}\right)_{2}$ supersaturated solution. 
strong interaction between monolayer and calcium ions (or strontium ions) and calcium ions (or strontium ions) could bind into the monolayers. On the other hand, as we can see, the limited area of DPPC on $\operatorname{Sr}\left(\mathrm{HCO}_{3}\right)_{2}$ supersaturated solution is lower than that of $\mathrm{Ca}\left(\mathrm{HCO}_{3}\right)_{2}$, which is resulted from the smaller solubility product of $\mathrm{SrCO}_{3}$ (compared with $\mathrm{CaCO}_{3}$ ). When the monolayer has adsorbed enough strontium ions, the local concentration of strontium carbonates under the monolayer was so high that the nucleation and crystallization thereafter appeared. In fact, we have noticed that there were micro-crystalline forming when the DPPC monolayer was compressed on the $\mathrm{Sr}\left(\mathrm{HCO}_{3}\right)_{2}$ supersaturate subphase. Actually, it's just because a much higher local concentration of $\mathrm{CaCO}_{3}$ and $\mathrm{SrCO}_{3}$ under the monolayers than that in bulk solution, the growth of calcium and strontium carbonates induced by the monolayer has achieved.

\subsection{Morphological Study of $\mathrm{CaCO}_{3}$ and $\mathrm{SrCO}_{3}$ Crystals}

Figure 2 shows the SEM image of calcium carbonate prepared in the bulk solution, air-water interface and the monolayer-water interface. As we can see, the morphologies of the obtained calcium carbonate are irregular and its size is not uniform without DPPC Langmuir monolayer (Figure 2(A), Figure 2(B)). In contrast, the crystals grown in the presence of monolayer of DPPC have a regular rhombohedral shape and relatively uniform size distribution (Figure 2(C)). In high magnification, as shown in Figure 2(D), we can easily find that the rhombohedral shape crystals with a size of $30 \mu \mathrm{m}$ in the length and width, also $10 \mu \mathrm{m}$ in thickness have been obtained.

Figure 3 is the corresponding SEM images of strontium carbonates. As the same as calcium carbonate, we can find that the morphology of the strontianites was powerfully affected by DPPC monolayer. The $\mathrm{SrCO}_{3}$ crystals were preferential forming strontianite needles in the absence of templating effects (Figure 3(A)). However, when the crystals grew underneath the DPPC Langmuir monolayer, they displayed well separate flowerlike morphology. The "flowers" are made up of bundles of strontianite needles as showed in Figure 3(D), which is the high magnification of a single flower in Figure 3(C).

\subsection{X-Ray Diffraction Meter Measurement.}

The structure of the crystal was confirmed by the XRD. Figure 4 shows the XRD pattern of calcium carbonate in the contrast experiment. The XRD spectrum of the calcium carbonate without the phospholipids monolayer exhibits multiple peaks, and all the peaks can be attributed to the rhombohedral phase of calcite (JCPDS 86-2339). Whereas, when the presence of monolayer, From Figure 4(A), we can see that there are only two peaks corresponding to (104) and (208) crystal planes of rhombohedral phase (JCPDS 86-2341) respectively, which exhibits the calcium carbonate have a well preferential orientation of (104) plane.

As for the strontium carbonates, however, we did not found this preferential orientation, In fact, from the XRD pattern (Figure 5), we can find that there are 

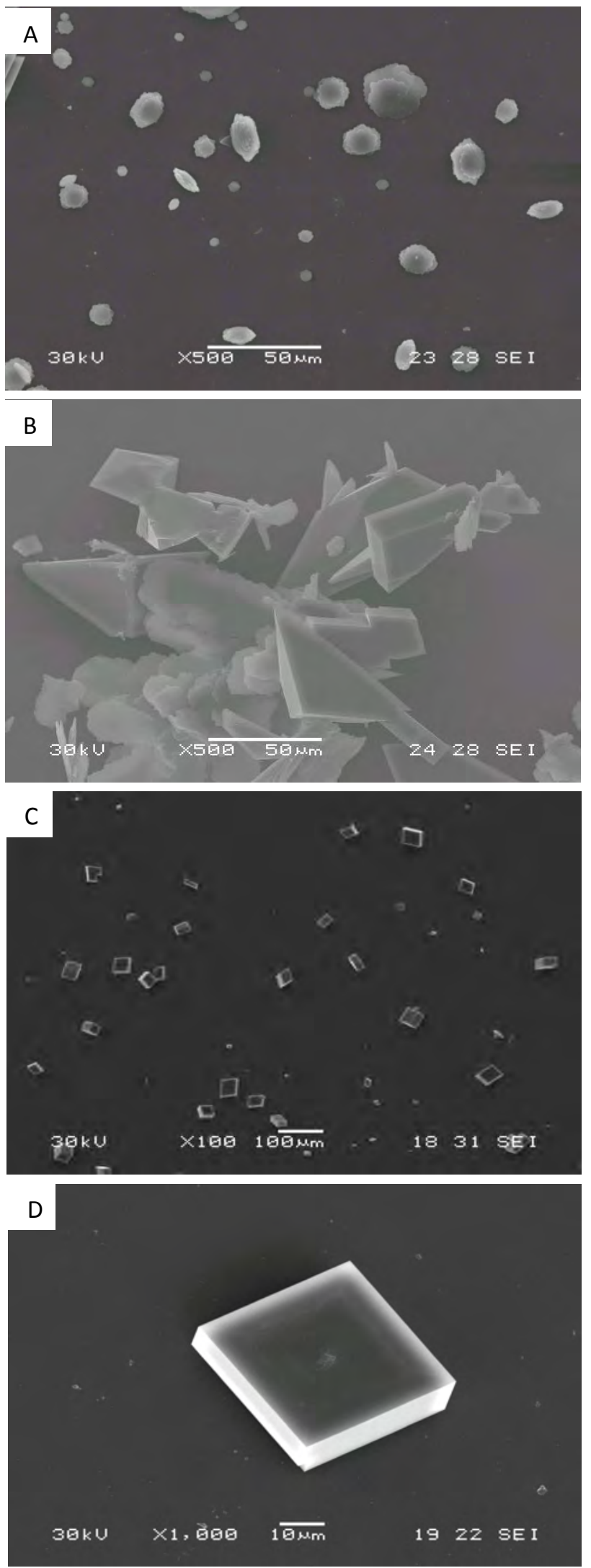

Figure 2. SEM images of $\mathrm{CaCO}_{3}$ grown at (A) bulk solution, (B) air-water interface, (C) monolayer-water interface and (D) is the higher magnification of $(C)$. 

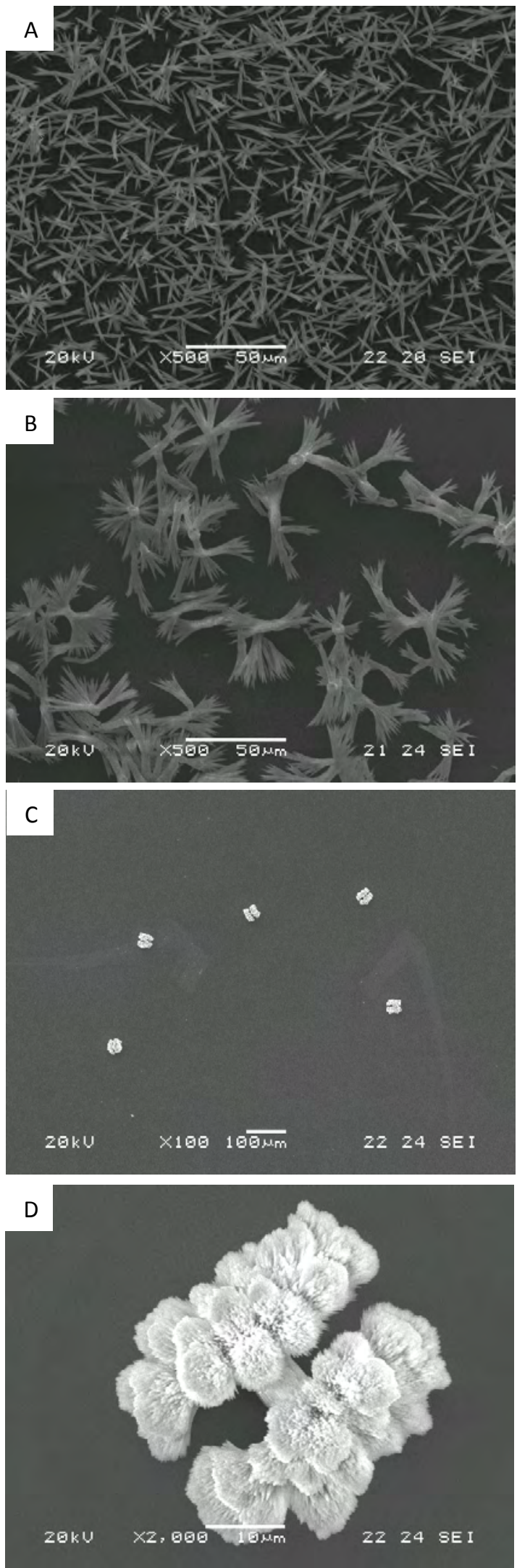

Figure 3. SEM images of $\mathrm{SrCO}_{3}$ grown at (A) bulk solution, (B) air-water interface, (C) monolayer-water interface and $(D)$ is the higher magnification of $(C)$. 


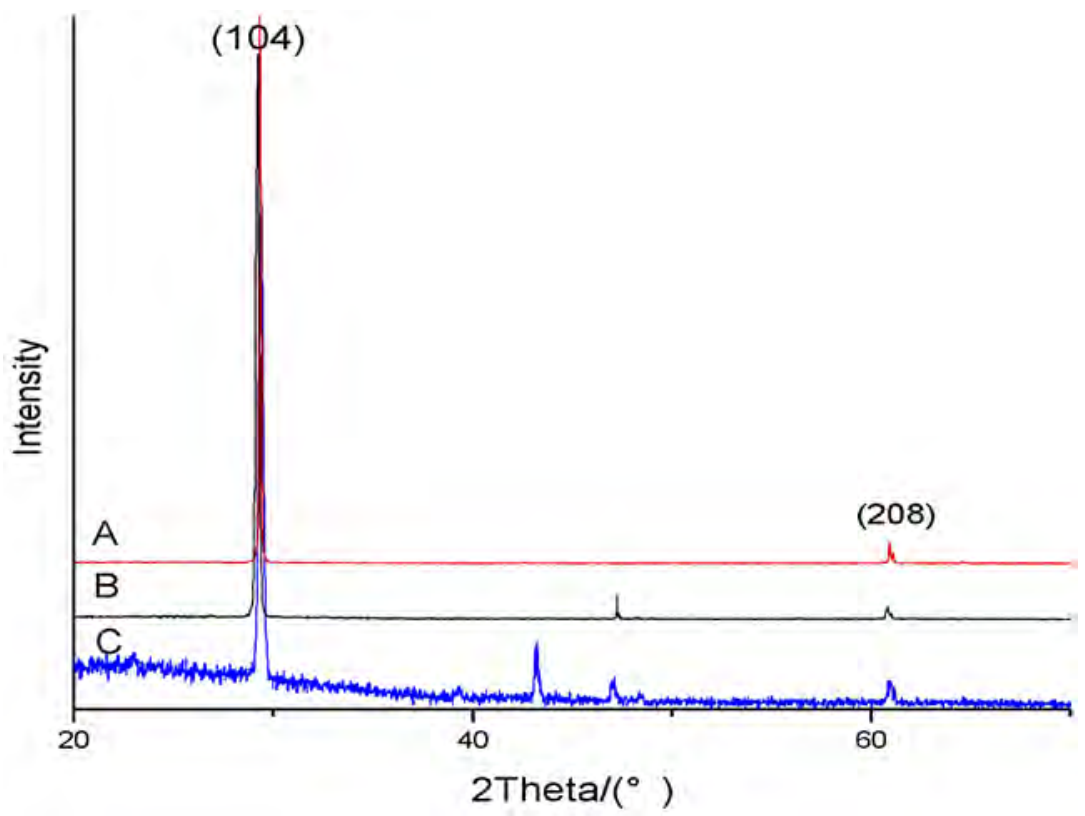

Figure 4. XRD patterns of $\mathrm{CaCO}_{3}$ grown at (A) monolayer-water interface, (B) air-water interface, $(\mathrm{C})$ bulk solution.

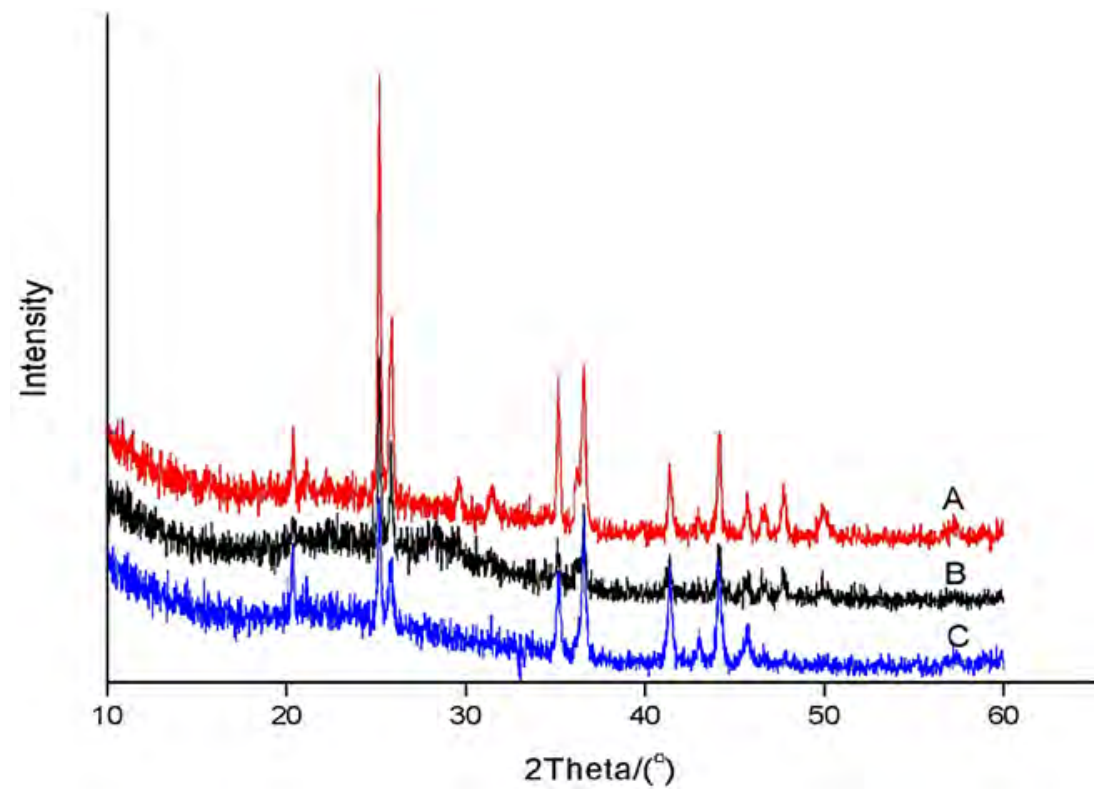

Figure 5. XRD patterns of $\mathrm{SrCO}_{3}$ grown at (A) monolayer-water interface, (B) air-water interface, $(\mathrm{C})$ bulk solution.

not clear difference in the three conditions, which indicate that the organic monolayer have little effect on the orientation of the strontium carbonates crystals.

\section{Discussions}

The above results clearly show that the DPPC Langmuir monolayer could powerfully affect the morphology, sizes and nucleation orientation of calcium carbonate. But covered with strontium carbonates, the monolayer didn't show ob- 
vious effect upon the crystal orientation, though the morphology has changed dramatically.

With regard to the two kinds of inorganic mineral, since $\mathrm{CaCO}_{3}$ has three polymorph, calcite, vaterite and aragonite, crystallisation of calcium carbonate is inevitably accompanied by the competing of the three phases. However, $\mathrm{SrCO}_{3}$ almost always crystallizes in the strontianite form, which have the same structure as aragonite. On the other hand, the monolayers of DPPC form hexagonal lattice in the surface pressure of $30 \mathrm{mN} / \mathrm{m}$ [21]. From the previous research, we know that $2 \mathrm{D}$ hexagonal lattice structure of the momalayer is likely to induce the calcite and vaterite polymorphs [22], aragonite configuration is difficult to achieve thereon. Therefore, the calcite polymorph of calcium carbonate has obtained in our experiment. At the same time, the monolayer may have a well lattice matching with the (104) plane of the calcite, as a result the crystallization of calcite phase with the (104) plane has been accelerated, while the other plane was inhibitory. Due to the hexagonal lattice of DPPC momolayer disfavour aragonite and cannot offer suitable mode for the epitaxy of strontium carbonates, we do not observe any obvious orientation control in the case of $\mathrm{SrCO}_{3}$.

The electrostatic interaction between the template and the minerals is another important factor in the process of crystallization. Concerning the molecular structure of DPPC, it is bearing the charged polar organic head group [23], which array along certain direction at the interface of the DPPC Langmuir monolayers subphase, and enable to absorb calcium ions or strontium ions at the lipid monolayer through electrostatic interaction, forming mental positive ions layer, followed by adsorption of counter ions, $\mathrm{HCO}_{3}^{-}$or $\mathrm{CO}_{3}^{2-}$. Thus, the concentration of precursor increase to its supersaturated degree for nucleation and the special nucleation sites were formed, which caused to the crystallization of the minerals. Meanwhile, from the point of molecular recognition, the arrangement and distances of the polar headgroups have affected the sizes and shapes of calcium carbonate and strontium carbonates formed.

From above discussion, it is clear that DPPC monolayer have different effect upon the crystallization of calcium carbonate and strontium carbonates. The different crystal structure is the answer. Aragonite polymorph of strontianite didn't have a fine lattice matching with the hexagonal lattice of DPPC momolayer, so, they cannot growth with a special orientation like the calcium carbonate. However, electrostatic attraction occurring at the inorganic-organic interface is equally crucial in the nucleation and growth of the two minerals. In the process of biomineralization, both lattice matching and electrostatic attraction play key role to direct and control the crystallization of minerals.

\section{Conclusion}

In summary, DPPC Langmuir monolayer has been used as template to compare the different effect upon the crystallization of calcium and strontium carbonates. The well-oriented (104) crystal plane of calcite and aragonite configuration of 
substantiate has been obtained in our experiment. Lattice matching and electrostatic attraction between the monolayers and subphase are essential factors of "molecular recognition" in biomineralization; both of them have critical effect to determine the size, morphology and nucleation orientation of the mineral.

\section{Acknowledgements}

This work was supported by the National Science Foundation of China, Grant No. 21203055 and Start-up funds for high-level introduction of talents for scientific research in Shanghai Publishing and Printing College.

\section{Conflicts of Interest}

The author declares no conflicts of interest regarding the publication of this paper.

\section{References}

[1] Li, H.Y. and Estroff, L.A. (2007) Hydrogels Coupled with Self-Assembled Monolayers: An in Vitro Matrix to Study Calcite Biomineralization. Journal of the American Chemical Society, 129, 5480-5483. https://doi.org/10.1021/ja067901d

[2] Li, W.W. and Gao, C. (2007) Efficiently Stabilized Spherical Vaterite $\mathrm{CaCO}_{3}$ Crystals by Carbon Nanotubes in Biomimetic Mineralization. Langmuir, 23, 4575-4582. https://doi.org/10.1021/la0632427

[3] Dai, H.X., Choe, W.S., Thai, C.K., Sarikaya, M., Traxler, B.A. and Schwartz, D.T. (2005) Nonequilibrium Synthesis and Assembly of Hybrid Inorganic-Protein Nanostructures Using an Engineered DNA Binding Protein. Journal of the American Chemical Society, 127, 15637-15643. https://doi.org/10.1021/ja055499h

[4] Weiner, S., Sagi, I. and Addadi, L. (2005) Choosing the Crystallization Path Less Traveled. Science, 309, 1027-1028. https://doi.org/10.1126/science.1114920

[5] Qiu, S.R., Wierzbicki, A., Salter, E.A., Zepeda, S., Orme, C.A., Hoyer, J.R., Nancollas, J.H., Cody, A.M. and Yoreo, J.J.D. (2005) Modulation of Calcium Oxalate Monohydrate Crystallization by Citrate through Selective Binding to Atomic Steps. Journal of the American Chemical Society, 127, 9036-9044. https://doi.org/10.1021/ja043591s

[6] Aizenberg, J., Hanson, J., Koetzle, T.F., Weiner, S. and Addadi, L. (1997) Control of Macromolecule Distribution within Synthetic and Biogenic Single Calcite Crystals. Journal of the American Chemical Society, 119, 881-886. https://doi.org/10.1021/ja9628821

[7] Ahmad, A., Rautaray, D. and Sastry, M. (2004) Biogenic Calcium Carbonate: Calcite Crystals of Variable Morphology by the Reaction of Aqueous $\mathrm{Ca}^{2+}$ Ions with Fungi. Advanced Functional Materials, 14, 1075-1080. https://doi.org/10.1002/adfm.200400005

[8] Nudelman, F., Gotliv, B.A., Addadi, L. and Weiner, S. (2006) Mollusk Shell Formation: Mapping the Distribution of Organic Matrix Components Underlying a Single Aragonitic Tablet in Nacre. Journal of Structural Biology, 153, 176-187. https://doi.org/10.1016/j.jsb.2005.09.009

[9] Muller, H., Zentel, R., Janshoff, A. and Janke, M. (2006) Control of $\mathrm{CaCO}_{3}$ Crystallization by Demixing of Monolayers. Langmuir, 22, 11034-11040.

https://doi.org/10.1021/la061637k 
[10] Sato, K., Kumagai, Y., Watari, K. and Tanaka, J. (2004) Hierarchical Texture of Calcium Carbonate Crystals Grown on a Polymerized Langmuir-Blodgett Film. Langmuir, 20, 2979-2981. https://doi.org/10.1021/la0360198

[11] Balz, M., Barriau, E., Istratov, V., Frey, H. and Tremel, W. (2005) Controlled Crystallization of $\mathrm{CaCO}_{3}$ on Hyperbranched Polyglycerol Adsorbed to Self-Assembled Monolayers. Langmuir, 21, 3987-3991. https://doi.org/10.1021/la047977s

[12] Shen, Q., Chen, Y., Wei, H., Zhao, Y., Wang, D. and Xu, D. (2005) Suspension Effect of Poly(styrene-ran-methacrylic Acid) Latex Particles on Crystal Growth of Calcium Carbonate. Crystal Growth \& Design, 5, 1387-1391.

https://doi.org/10.1021/cg0496311

[13] Zhang, L.J., Liu, H.G., Feng, X.S., Zhang, R.J., Zhang, L., Mu, Y.D., Hao, J.C., Qian, D.J. and Lou, Y.F. (2004) Mineralization Mechanism of Calcium Phosphates under Three Kinds of Langmuir Monolayers. Langmuir, 20, 2243-2249. https://doi.org/10.1021/la035381j

[14] Naka, K., Tanaka, Y. and Chujo, Y. (2002) Effect of Anionic Starburst Dendrimers on the Crystallization of $\mathrm{CaCO}_{3}$ in Aqueous Solution: Size Control of Spherical Vaterite Particles. Langmuir, 18, 3655-3658. https://doi.org/10.1021/la011345d

[15] Meldrum, F.C. (2003) Calcium Carbonate in Biomineralisation and Biomimetic Chemistry. International Materials Reviews, 48, 187-224. https://doi.org/10.1179/095066003225005836

[16] Buijnsters, P.J.J.A., Donners, J.J.J.M., Hill, S.J., Heywood, B.R., Nolte, R.J.M., Zwanenburg, B. and Sommerdijk, N.A.J.M. (2001) Oriented Crystallization of Calcium Carbonate under Self-Organized Monolayers of Amide-Containing Phospholipids. Langmuir, 17, 3623-3628. https://doi.org/10.1021/la001765n

[17] Sastry, M., Kumar, A., Damle, C., Sainkar, S.R., Bhagwat, M. and Ramaswamy, V. (2001) Crystallization of $\mathrm{SrCO}_{3}$ within Thermally Evaporated Fatty Acid Films: Unusual Morphology of Crystal Aggregates. CrystEngComm, 3, 81-83. https://doi.org/10.1039/b102707g

[18] Kuther, J., Bartz, M., Seshadri, R., Vaughan, G.B.M. and Tremel, W. (2001) Crystallization of $\mathrm{SrCO}_{3}$ on a Self-Assembled Monolayer Substrate: An In-Situ Synchrotron X-Ray Study. Journal of Materials Chemistry, 11, 503-506. https://doi.org/10.1039/b008097g

[19] Whipps, S., Khan, S.R., O’Palko, F.J., Backov, R. and Talham, D.R. (1998) Growth of Calcium Oxalate Monohydrate at Phospholipid Langmuir Monolayers. Journal of Crystal Growth, 192, 243-249. https://doi.org/10.1016/S0022-0248(98)00426-6

[20] Yasushi, K. (1962) The Behavior of Various Inorganic Ions in the Separation of Calcium Carbonate from a Bicarbonate Solution. Bulletin of the Chemical Society of Japan, 35, 1973-1980. https://doi.org/10.1246/bcsj.35.1973

[21] Lakshminarayanan, R., Kini, R.M. and Valiyaveettil, S. (2002) Investigation of the Role of Ansocalcin in the Biomineralization in Goose Eggshell Matrix. PNAS, 99, 5155-5159. https://doi.org/10.1073/pnas.072658899

[22] Kuther, J., Nells, G., Seshadri, R., Schaub, M., Butt, H.-J. and Tremel, W. (1998) Templated Crystallisation of Calcium and Strontium Carbonates on Centred Rectangular Self-Assembled Monolayer Substrates. Chemistry-A European Journal, 4, $1834-1842$.

https://doi.org/10.1002/(SICI)1521-3765(19980904)4:9<1834::AID-CHEM1834>3.0. CO;2-6

[23] Collier, J.H. and Messersmith, P.B. (2001) Phospholipid Strategies in Biomineralization and Biomaterials Research. Annual Review of Materials Research, 31, 237-263. https://doi.org/10.1146/annurev.matsci.31.1.237 